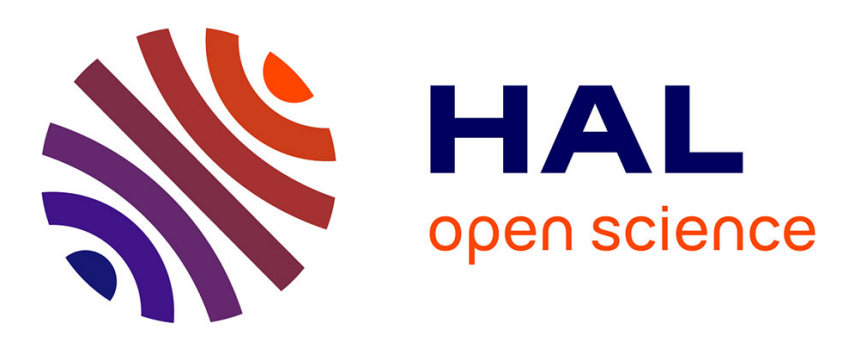

\title{
On the use of low barrier potential materials to improve high frequency coupling to Josephson tunnel junctions
}

\author{
P. Cardinne, J. Nordman, Maurice Renard
}

\section{To cite this version:}

P. Cardinne, J. Nordman, Maurice Renard. On the use of low barrier potential materials to improve high frequency coupling to Josephson tunnel junctions. Revue de Physique Appliquée, 1974, 9 (1), pp.167-171. 10.1051/rphysap:0197400901016700 . jpa-00243731

\section{HAL Id: jpa-00243731 https://hal.science/jpa-00243731}

Submitted on 1 Jan 1974

HAL is a multi-disciplinary open access archive for the deposit and dissemination of scientific research documents, whether they are published or not. The documents may come from teaching and research institutions in France or abroad, or from public or private research centers.
L'archive ouverte pluridisciplinaire HAL, est destinée au dépôt et à la diffusion de documents scientifiques de niveau recherche, publiés ou non, émanant des établissements d'enseignement et de recherche français ou étrangers, des laboratoires publics ou privés. 


\title{
ON THE USE OF LOW BARRIER POTENTIAL MATERIALS TO IMPROVE HIGH FREQUENCY COUPLING TO JOSEPHSON TUNNEL JUNCTIONS
}

\author{
P. CARDINNE \\ L'Air Liquide, Centre d'Etudes Cryogéniques, BP 15, 38360 Sassenage, France \\ J. NORDMAN \\ University of Wisconsin, Dept. of Elect. Engr. Madison, Wisconsin 53706, USA
}

\section{RENARD}

Centre de Recherches sur les Très Basses Températures, CNRS

avenue des Martyrs, BP 166, 38042 Grenoble, France

\begin{abstract}
Résumé. - L'amélioration du couplage des jonctions tunnel Josephson doit passer soit par des techniques de transformation d'impédance soit par la fabrication de jonctions dont les valeurs d'impédance sont plus appropriées. Deux calculs de l'efficacité du couplage jonction-cavité, l'un avec une antenne, l'autre avec une boucle d'induction, mettent en évidence l'importance du terme $I_{\mathrm{c}} r_{0} / \Gamma$ où $\Gamma$ est la capacité, $I_{\mathrm{c}}$ le courant critique et $r_{0}$ une dimension liée à la taille de la jonction. Il existe plusieurs façons d'accroître ce "facteur de mérite ». Si l'on considère seulement les phénomènes tunnel, il y a avantage à décroître la hauteur de la barrière de potentiel. Les semiconducteurs ont été employés comme barrière parce qu'il est possible soit d'utiliser une bande interdite naturellement étroite, soit encore d'utiliser les propriétés de l'interface métal semiconducteur pour avoir de petites hauteurs de barrière. On trouvera ci-après une revue des travaux expérimentaux sur l'utilisation de matériaux ayant de faibles hauteurs de barrière. Des essais ont été faits en déposant les matériaux suivants : Te, $\mathrm{PbTe}, \mathrm{CdS}, \mathrm{CdSe}, \mathrm{Ge}, \mathrm{InSb}$, etc..., essais qui n'ont généralement pas encore été couronnés de succès. Parmi les problèmes rencontrés, signalons les plus importants : existence d'états de surface, variation du dopage en fonction du temps, diffusion près de l'interface, trous d'épingle, comportement amorphe-polycristallin, etc... De plus, ces différents phénomènes peuvent mener à plusieurs mécanismes possibles en vue d'expliquer la conduction dans les sandwiches supraconducteur-semiconducteur-supraconducteur. Certains de ces mécanismes ne sont pas compatibles avec un bon couplage jonction-haute fréquence.
\end{abstract}

Abstract. - Improved high frequency coupling to Josephson tunneling junctions must involve impedance transformation techniques or the fabrication of junctions with more appropriate impedance values. Two kinds of calculations about efficiency of junction coupling with a cavity, one with an antenna and another with an inductive loop show clearly the importance of the term $I_{\mathrm{c}} r_{0} / \Gamma$ where $\Gamma$ is the capacitance, $I_{\mathrm{c}}$ the critical current and $r_{0}$ a dimension related to the size of the junction. Several ways may be proposed to increase this «figure of merit». It appears that, when considering only tunneling phenomena, there is an advantage to decrease the barrier potential height. A number of people have employed semiconductors as barriers because it is possible to use either a naturally narrow forbidden band, or to use the metal-semiconductor interface properties, to get small barrier heights. This paper is devoted to a review of experimental works on junctions using low barrier materials. Attempts have been made with various deposited materials such as Te, PbTe, CdS, CdSe, Ge, InSb, etc., ... But at the present time these trials have not yet been clearly successful. Many problems are related to the use of these materials, some of the more important being : presence of surface states, variation of doping with time, diffusion near the interface, pinholes and amorphous-polycrystalline behaviour. Moreover, these various phenomena can lead to several possible mechanisms for explaining conduction in superconductor-semiconductor-superconductor sandwiches. Some of these mechanisms are not compatible with good high frequency coupling.

Introduction. - Even though stable Josephson tunnel junctions have now been made in a reliable and repeatable manner by a number of people, little progress seems to have been made in using them for high frequency applications. The usual reason cited is that the tunnel junction capacitance is inherently large and that it serves to short the junction at high frequencies. The purposes of this paper are to review the possible ways to alleviate this problem and in particular to review the work on deposited semiconductors used 
to produce barriers with reduced barrier height, enabling thicker, and hence lower capacitance junctions.

1. Junctions figure of merit. - For junctions of dimensions $r_{0}$ larger than $\lambda_{\mathrm{J}}$, the Josephson penetration depth, no calculations have been done for the coupling with a cavity. But the existence of internal resonances seems to provide a way of nonradiative dissipation of energy. So it seems that an increase of the size of the junction beyond $\lambda_{\mathrm{J}}$ is uneffective in giving higher emitted power. If $r_{0}<\lambda_{\mathrm{J}}$ the junction can be represented by the Josephson element (non linear inductor), in parallel with a resistor and a capacitor. For low frequencies the resistance predominates and a useful figure of merit is the factor $I_{\mathrm{c}} R$, where $I_{\mathrm{c}}$ is the Josephson DC critical current. This term is fixed in a tunnel junction at [1] :

$$
I_{\mathrm{c}} R=I_{\mathrm{c}} R_{\mathrm{N}} \frac{R(V)}{R_{\mathrm{N}}} \simeq \frac{\pi}{2 \Delta} \frac{R(V)}{R_{\mathrm{N}}} \gg \Delta
$$

where $R_{\mathrm{N}}$ is the resistance of the junction in the normal state, and $R(V)$ is the voltage dependent resistance due to quasi-particle tunneling.

For other types of weak links, the value of $I_{\mathrm{c}} R_{\mathrm{N}}$ appears to be of similar magnitude [2], but usually there is no increase in $R$ below $T_{\mathrm{c}}$ for any device other than a tunnel junction, which appears optimum.

For high frequencies, capacitive reactance becomes predominant in good junctions, and a detailed analysis [3], [4] gives for the emitted power $W_{\mathrm{r}}$, a product of two terms : the first related to the cavity and especially its $Q$ factor, the other related to the junction. Assuming a $Q$ of 5000 we obtain :

$$
\underset{\text { (watts) }}{W_{\mathrm{r}}}=5 \times 10^{-13} \frac{a^{2} j_{\mathrm{c}}}{\varepsilon^{2}} \frac{\left(r_{0}\right)^{2}}{\left(\lambda_{\mathrm{J}}\right)^{2}} .
$$

$a$ being the thickness of insulator in angströms, $j_{\mathrm{c}}$ the critical current density in $\mathrm{A} / \mathrm{cm}^{2}, \varepsilon$ the dielectric constant, $r_{0}$ the dimension of the junction. Assuming $r_{0}=\lambda_{\mathrm{J}}$, the technical limitations for evaporated junctions being about $1 \mu$, give limitation of $j_{\mathrm{c}}$ of the order of $10^{5}$. But, as we shall see the experimental values are always lower, say below or around $10^{3}$. Since the size-limitation of $j_{c}$ is not now obtained, it seems reasonable to try to increase $j_{\mathrm{c}}$, without decreasing too much the thickness $a$, and this can be obtained in principle by a decrease in the effective potential barrier $\varnothing$ of the insulator, i. e. by using a semiconductor.

2. Oxide junction accomplishments. - Typical oxide junctions have values of $J_{\mathrm{c}}$ between 0.1 and $10^{2} \mathrm{~A} / \mathrm{cm}^{2}$, and capacitances between $5 \times 10^{-7}$ and $10^{-5} \mathrm{~F} / \mathrm{cm}^{2}[5]$, this gives a range of possible powers in the conditions described previously

$$
5 \times 10^{-11}<W_{\mathrm{r}}<5 \times 10^{-9} .
$$

The work on very small area high current density junctions first by Schroen [6] and now by Jutzi et al. [7] may have increase $W_{\mathrm{r}}$ to near a practical maximum of about $5 \times 10^{-8}$. In addition to the technological problem of making small sized junctions the values of $I_{\mathrm{c}}$ becomes noise limited as noticed by Jutzi [7] in a $1.25 \times 3.1 \mu$ junction.

3. Semiconducting junctions, objectives. - Assuming that an increase in current density beyond $10^{4}$ is impractical, the only way to obtain a further increase in $W_{\mathrm{r}}$ is to decrease the capacitance. This can be done by an increase in $a$, keeping the product $(a \sqrt{\varnothing})$ constant to keep the same tunneling probability. Furthermore we have to choose materials with not too high values of $\varepsilon$. Assuming oxide barriers heights of about $1 \mathrm{eV}$ [8], it would appear that a reduction in $\varnothing$ of 100 and hence an increase in $a$ of 10 is attainable, by the use of a semiconductor.

3.1 SEMICONDUCTOR JUNCTION. REAL ACCOMPLISHMENTS. - Semiconductor barriers for superconductive tunnel junctions have been attempted by a number of people. Table $I$ is a summary of some of the results of these studies [9]-[24]. The semiconductors were vacuum deposited films of many materials including $C$, Ge, Te, InSb, GaAs, $\mathrm{CdS}, \mathrm{CdSe}, \mathrm{ZnS}$ and $\mathrm{PbTe}$. The following observations are of importance :

1) Quasi-particule tunneling was not always observed and when it was, excess currents for $V<2 \Delta$ were quite common. These are not « good» junctions, and even at high frequencies the conductance term can overshoot the reactance of the capacity, decreasing strongly the emitted radiation.

2) In most cases it was necessary to oxidize after depositing the semiconductor to avoid shorts presumably through pinholes.

3) With the exception of CdS and possibly $C$ the estimated barrier heights for barriers thin enough to exhibit Josephson tunneling were all greater than $125 \mathrm{mV}$.

4) Capacitance data is almost non existent.

5) Josephson tunneling was seen in $\mathrm{CdS}, \mathrm{Te}, \mathrm{PbTe}$, $\mathrm{Ge}$ and InSb barriers. Only $\mathrm{Ge}$, Te and InSb exhibited current densities above $20 \mathrm{~A} / \mathrm{cm}^{2}$ with, however, extremely thin $(\simeq 50 \AA)$ layers. From this it must be concluded that there is yet no evidence that a low capacitance, high current density junction can be fabricated with deposited semiconductor barriers. We now review some of the problems.

3.2 Pinholes. - With the possible exception of carbon the deposited semiconductor films will normally contain voids or pinholes even if they are as thick as $1000 \AA$. These voids may be macroscopic or microscopic in size [25] but the net effect is similar, a parallel conduction path is provided around the 
TABLE I

\section{Superconductor-semiconductor-superconductor tunnel junctions}

\begin{tabular}{|c|c|c|c|c|c|c|c|c|c|}
\hline $\begin{array}{lc} & \text { Source } \\
\text { CdS } & -\end{array}$ & $\begin{array}{c}\text { Junction } \\
\text { type } \\
-\end{array}$ & $\begin{array}{l}\text { Quasi- } \\
\text { particle } \\
\text { tunneling }\end{array}$ & $\begin{array}{l}\text { Oxidize } \\
\text { pinhole } \\
-\end{array}$ & $\begin{array}{c}\text { Average } \\
\varnothing \text { bar- } \\
\text { rier } \\
\text { mV } \\
-\end{array}$ & $\begin{array}{c}\varnothing \\
\text { sur- } \\
\text { face } \\
\mathrm{mV} \\
-\end{array}$ & $\begin{array}{c}\text { How } \\
\text { barrier } \\
\text { is } \\
\text { obtained } \\
\text { - }\end{array}$ & $\begin{array}{l}d \\
\AA \\
-\end{array}$ & $\begin{array}{c}J_{\mathrm{c}} \\
\mathrm{A} / \mathrm{cm}^{2} \\
-\end{array}$ & $\begin{array}{l}I_{\mathrm{c}} \mathrm{vsH} \\
-\end{array}$ \\
\hline Giaever [8] & $\mathrm{Pb}-\mathrm{CdS}-\mathrm{Pb}$ & yes & yes & 25 & & VI curve & $200-300$ & & \\
\hline & Sn-CdS-Sn & yes & yes & & & & 75 & 0.08 & \\
\hline Giaever et Zeller [10] & $\begin{array}{l}\text { Sn-CdS-Sn } \\
\text { Pb-CdS-TI } \\
\text { Pb-CdS-Pb } \\
\mathrm{In}_{y}\end{array}$ & $\begin{array}{l}\text { yes } \\
\text { poor } \\
\text { good }\end{array}$ & & & & & & 0.01 & - \\
\hline $\begin{array}{l}\text { Dynes et Fulton [11] } \\
\text { McVicar et al. }[12]\end{array}$ & Sn-CdS-Sn & & & & & & 130 & 0.05 & periodicity \\
\hline Russo [13] & Pb-CdS-Pb & yes & yes & & & & $60-500$ & 0.01 & \\
\hline \multicolumn{10}{|l|}{$\underline{\mathrm{CdSe}}$} \\
\hline \multicolumn{10}{|l|}{ Lubberts et } \\
\hline Shapiro [14] & $\begin{array}{l}\text { Sn-CdSe-Sn } \\
\text { Sn-CdSe-Sn }\end{array}$ & yes & yes & 125 & & VI curve & $\begin{array}{c}50-100 \\
100\end{array}$ & & \\
\hline Rissman [15] & $\mathrm{Nb}-\mathrm{CdSe}-\mathrm{Pb}$ & yes (leakage) & yes et no & & & & 50 & & \\
\hline \multicolumn{10}{|l|}{$\underline{\mathrm{C}}$} \\
\hline McVicar et al. [12] & $\mathrm{Pb}-\mathrm{C}-\mathrm{Pb}$ & yes (leakage) & no & & & vsT & $90-270$ & & \\
\hline McVicar et al. [16] & $\begin{array}{l}\text { Sn-C-Pb } \\
\mathrm{Nb}(\mathrm{Re})-\mathrm{G}-\mathrm{In} \\
\mathrm{Pb}(\mathrm{Sn})-\mathrm{C}-\mathrm{Pb}\end{array}$ & yes (leakage) & $\begin{array}{l}\text { no } \\
\text { no } \\
\text { no }\end{array}$ & $\begin{array}{c}25 \\
300 \\
35 \rightarrow 3.5\end{array}$ & & & $\begin{array}{r}140 \\
220 \\
70\end{array}$ & & \\
\hline \multicolumn{10}{|l|}{$\underline{\mathrm{Te}}$} \\
\hline Cardinne [17] & $\mathrm{Pb}-\mathrm{Te}-\mathrm{Pb}$ & yes (leakage) & yes & & & & $100-200$ & $2-500$ & periodicity \\
\hline Seto et van Duzer [18] & $\mathrm{Pb}-\mathrm{Te}-\mathrm{Pb}$ & no (?) & yes & & 175 & & $400-200$ & $0.02-15$ & good \\
\hline \multicolumn{10}{|l|}{$\mathrm{Ge}$} \\
\hline $\begin{array}{l}\text { Giaever et Zeller [20] } \\
\text { McVicar et al. [12] }\end{array}$ & $\begin{array}{l}\text { Sn-Ge-Sn } \\
? \mathrm{Ge} ?\end{array}$ & & $\begin{array}{l}\text { yes } \\
\text { yes }\end{array}$ & & & & 100 & & \\
\hline $\begin{array}{l}\text { Keller et Nordman [21] } \\
\text { [22] }\end{array}$ & $\mathrm{Nb}-\mathrm{Ge}-\mathrm{Pb}(\mathrm{Sn})$ & yes & yes & $50-120$ & & VI curve & 50 & $20-40$ & periodicity \\
\hline $\begin{array}{l}\text { Lipson et Stupel [23] } \\
\text { Konig [24] }\end{array}$ & $\begin{array}{l}\mathrm{Sn}-\mathrm{Ge}-\mathrm{Sn} \\
\mathrm{Al}-\mathrm{Ge}-\mathrm{Pb}\end{array}$ & $\begin{array}{l}\text { no } \\
\text { yes }\end{array}$ & $\begin{array}{l}\text { no } \\
\text { no }\end{array}$ & & & & $\begin{array}{l}290-3000 \\
250-800\end{array}$ & 10 & \\
\hline \multicolumn{10}{|l|}{ Others } \\
\hline $\begin{array}{l}\text { Cardinne [26] } \\
\text { Keller et }\end{array}$ & $\mathrm{Pb}-\mathrm{PbTe}-\mathrm{Pb}$ & yes (leakage) & yes & & & & 200 & $40(?)$ & \\
\hline $\begin{array}{l}\text { Nordman [21], [22] } \\
\text { Keller et Nordman [21 }\end{array}$ & $\begin{array}{l}\mathrm{Nb}-\mathrm{InSb}-\mathrm{Pb} \\
\text { 1] } \mathrm{Nb}-\mathrm{GaAs}-\mathrm{Pb}\end{array}$ & $\begin{array}{l}\text { yes } \\
\text { yes }\end{array}$ & $\begin{array}{l}\text { yes } \\
\text { yes }\end{array}$ & $600-150$ & & VI curve & 50 & & periodicity \\
\hline Giaever et Zeller [20] & $\mathrm{Sn}-\mathrm{ZnS}-\mathrm{Sn}$ & $(\mathrm{Pb}, \mathrm{Al})$ yes & yes & & & & 30 & & \\
\hline
\end{tabular}

semiconductor. If the base superconductor oxidizes readily the usual solution is to oxidize the metal in the pinholes after the semiconductor deposition. However this procedure probably also produces a series barrier, either by oxidation of the semiconductor surface or of the initial layer of the deposited upper superconductor. This second oxidation can be brought about through adsorbed oxygen on the semiconductor. Evidence for this effect can perhaps be seen from the results on $\mathrm{Te}$ by Seto and van Duzer, where the Te is degenerate and the Josephson effect is similar to that of an S-N-S junction but where a series barrier limits the conductance. It is also evident in the results of Keller and Nordman on Ge and McVicar on $C$ where the apparent barrier potential increases rapidly as the thickness decreases. The unfortunate conse- quences of this are a limitation on maximum critical current density and a larger than expected capacitance for the high current density junctions. The pinhole oxidation problem is consequently not trivial. One must somehow oxidize the pinholes sufficiently to eliminate their contribution to conduction but at the same time a significant series barrier must be prohibited from growing or removed after forming.

3.3 Barrier height values. Surface states. It would appear that the method of choosing a semiconductor material to provide a low barrier height is not at all obvious. The following things must be considered.

1) Although work function differences between semiconductor and electrodes materials may be known 
this often has little relation to the actual interface conditions which are dominated by impurities, dangling bonds, diffused atoms, etc... Certain qualitative facts are useable, such as the tendency for group IV and III-V compounds to have the surface Fermi level fixed by surface states deep within the forbidden gap [25]. This may produce Schottky barriers on the surface giving rise to the same effects as a series oxide.

2) Although in bulk form materials like Ge and InSb can be doped in a controllable manner with impurities to produce a known Fermi level position relative to the conduction or valence bands, it is virtually impossible to control doping in films, the lattice imperfections usually producing a doping level in themselves. In fact the films may be amorphous (in many cases this is the most likely form) and exhibit a wide range of behavior dependent upon deposition rate, temperature, substrate, and ageing. For example, we originally tried InSb because its band gap is significantly smaller than $\mathrm{Ge}$, allowing for some comparison of results. However it was found that both our sputtered $\mathrm{Ge}$ and $\mathrm{InSb}$ are amorphous and that amorphous InSb has a gap quite comparable to that of $\mathrm{Ge}$.

3) Interdiffusion between semiconductor and electrode may be significant. The data of Cardinne on Te differ from Seto and van Duzer in that we do not obtain high conductivity degenerate material. A definite barrier is produced as evidenced by the appearance of superconductor gap structure in the voltampere characteristic. However the apparent gap is reduced from that of pure $\mathrm{Pb}$ and in fact the curve resembles, in shape, that of a proximity effect SMIS junction [26]. We believe this effect is due to interdiffusion of $\mathrm{Pb}$ and $\mathrm{Te}$ possibly producing a $\mathrm{PbTe}$ layer.

3.4 BARRIER MODELS. - The ideal barrier would have the shape shown in figure $1 a$. It represents an « $\mathrm{n}$ » (or $\mathrm{p}$-) type semiconductor with large energy gap (to inhibit free carriers) and with the Fermi energy fixed within about $20 \mathrm{mV}$ of the gap edge. Allowing for work function difference between metal and semiconductor figure $1 b$ may be more realistic with $\mathrm{PbTe}$ for example [26]. It is possible that such behavior occurs in illuminated CdS but because of the low current densities seen it would appear that the model is more like figure $1 a$ with perhaps rather small but significant space charge regions near the surfaces. If doping is insufficient, this space charge layers can easily extend across the whole width, leading to a short circuit behavior.

In the Te junctions of Seto and van Duzer and the $\mathrm{Ge}$ and InSb junctions of Keller and Nordman the behavior with reduced thickness can be explained with models like figures $2 a$ and $2 b$. The materials are $\mathrm{p}$ type and in the case of Te the doping inside the material is degenerate so that two barriers existe separated

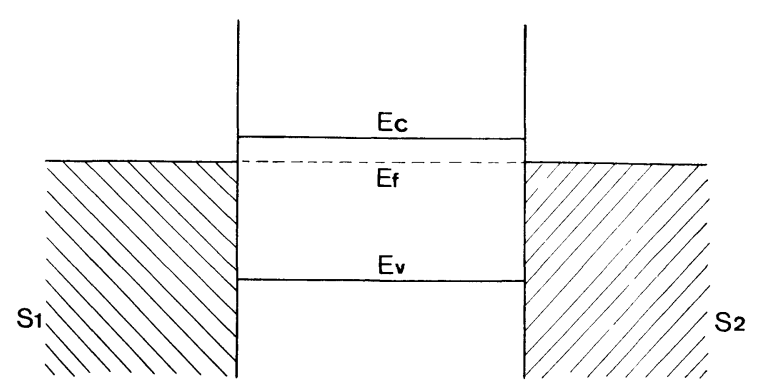

(a)

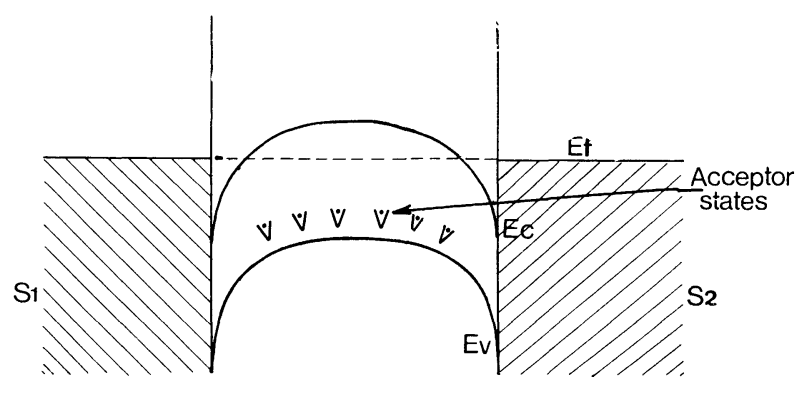

(b)

FIg. 1. - Energy Barrier models : a) Ideal barrier ; $b$ ) Proposed model without surface states.

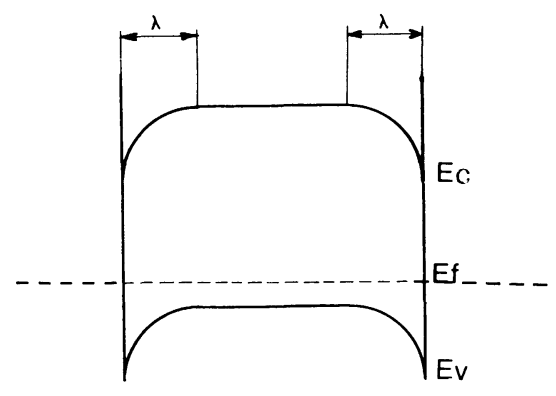

[a ]

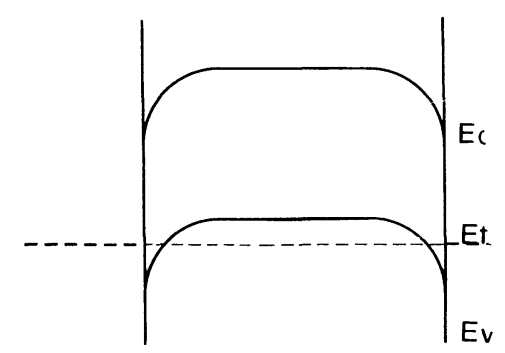

[b]

Fig. 2. - Energy barrier models with surface states : $a$ ) Amorphous material $(\mathrm{Ge}, \mathrm{InSb}) ; b)$ Degenerate tellurium «p-type ».

by a conductor. Both $\mathrm{Te}$ and $\mathrm{Ge}$ are surface state dominated and hence such a model is reasonable. Because the $\mathrm{Ge}$ is amorphous with many trapping states it is not unreasonable that this surface barrier width can be much less than $50 \AA$.

The measured low current densities and the known dominance of surface states in $\mathrm{Te}, \mathrm{Ge}, \mathrm{InSb}, \mathrm{ZnS}$, GeAs, CdSe would seem to support the conclusion 
that a high barrier space charge region limits $I_{c}$ and hence the usefulness of these materials for tunneling barriers. One must be careful not to condemn them completely, however, because of the following four facts :

1) The relative importance of a surface oxide is unknown.

2) It may be possible to reduce the effective barrier height to acceptable values with sufficient doping or production of trap levels (i. e. by bombardment).

3) If the center is degenerate one may obtain effectively a S-N-S junction with a fairly high resistance $N$ region. This apparently was done by Seto and van Duzer and it remains to be seen if a sufficiently thick Te layer causes the current be limited only by the center region and if $I_{\mathrm{c}} R_{\mathrm{N}}$ can be increased above its apparently very low value of $\simeq 4 \mu \mathrm{V}$ for a $700 \AA$ device. With this thickness and with thinner devices, although the DC resistance is higher than other SNS junctions, the series Schottky barriers serve to reduce performance because they limit $I_{c}$ rather drastically and add capacitance.

A barrier model like figure $1 b$ would appear optimum. Unfortunately however the number of well known, easily deposited materials for which the Fermi energy is not surface state dominated are not numerous. Many polar materials with low surface state dependence such as $\mathrm{ZnS}$ and $\mathrm{SiO}_{2}$ have very large energy gaps and present little hope for doping a film such that the Fermi level is close to valence or conduction band. Small gap materials like SnTe and PbTe have very large frequency dependent permittivity values (75-1 280 for SnTe [27]).

4. Conclusion. - The possibility remains for using a deposited semiconductor barrier to produce a Josephson tunnel junction superior to present oxide junctions for high frequency applications. However, although research to date has been far from exhaustive, both experimental results and theoretical considerations are somewhat discouraging. Progress has been hampered by the difficulties surrounding the measurement and control of electrical, structural, and chemical properties of extremely thin films.

Attempts to increase current densities above $\simeq 50 \mathrm{~A} / \mathrm{cm}^{2}$ have not been successful presumably because of a series oxide or large Schottky barrier caused by surface states. Control over adsorbed oxygen and other impurities is difficult because of conflicting requirement such as the necessity for pinhole oxidation.

\section{References}

[1] Ambegaokar, V. and Baratoff, A., Phys. Rev. Lett. 10 (1963) 486 ; 11 (1963) 104.

[2] Gregers-Hansen, P. and Levinsen, M. T., Phys. Rev. Lett. 17 (1971) 847.

[3] RENARD, M., to be published.

[4] Renard, M. and Marti, C., to be published.

[5] Fulton, T. A., Dynes, R. C. and Anderson, P. W., Proc. I. E. E. E. 61 (1973) 28.

[6] Schroen, W., J. Appl. Phys. 39 (1968) 2671.

[7] Jutzi, W., MoR., Th. O., Gasser, M. and Eschwind, H. P., Electron. Lett. 8 (1972) 859.

[8] Eldidide, J. M. and Matisoo, J., LT 12, 427.

[9] Giaever, I., Phys. Rev. Lett. 20 (1968) 1286.

[10] Giaever, I. and Zeller, H. R., Phys. Rev. B 1 (1970) 4278.

[11] Dynes, R. C. and Fulton, T. A., Phys. Rev. B 3 (1971) 3015.

[12] McVicar, M. L. A., Freake, S. M. and Adkins, J. C., Jour. Vac. Sci. \& Tech. 6 (1969) 717.

[13] Russo, M., Atti del Congresso di Cibernetica, Casciana Terme 424 (1971).
[14] Lubberts, G. and Shapiro, S., J. Appl. Phys. 43 (1972) 3958.

[15] Rissman, P., J. Appl. Phys. 44 (1973) 1893.

[16] MCVicar, M. L. A., J. Appl. Phys. 41 (1970) 4765.

[17] Cardinne, P., Marti, C. and Renard, M., Revue Phys. Appl. 6 (1971) 547-550.

[18] Seto, J. and van Duzer, T., Appl. Phys. Lett. 19 (1971) 488.

[19] Seto, J. and van Duzer, T., LT 13.

[20] Giaever, I. and Zeller, H. R., Phys. Rev. Lett. 21 (1968) 1385.

[21] Keller, W. H. and Nordman, J. E., J. Appl. Phys. 42 (1971) 137.

[22] Keller, W. H. and Nordman, J. E., to be published.

[23] Lipson, S. and Stupel, M. M., Phys. Lett. 33A (1970) 493.

[24] Konig, B., Phys. Lett. 39A (1972) 117.

[25] Mead, C. A., Solid. State Electron. 9 (1966) 1023.

[26] Cardinne, P., Manhes, B. and Renard, M., Appl. Applied Superconductivity Conf., Annapolis, May 1972.

[27] Burstein, Pinezuk, A. and Wallis, R. F., J. Phys.\&.Chem. Solids, Supplement 1, 32 (1971) 251. 